\title{
Relação das teses e dissertações defendidas no Programa de Pós-Graduação Stricto Sensu em Educação da Universidade São Francisco no período de junho a novembro de 2015
}

LEITE, Marcelo. Ensino integrado no IFSULDEMINAS - do documento à implantação: um olhar pela janela da governamentalidade. 2015. 167p. Tese (Doutorado em Educação). Programa de Pós-Graduação Stricto Sensu em Educação, Universidade São Francisco, Itatiba, SP. Orientadora: Profa. Dra. Ana Paula de Freitas.

O ensino profissional no Brasil é caracterizado por constantes transformações na forma de atuação e na organização curricular, tendo nas práticas educativas uma constante dicotomia entre disciplinar/integrado, pensar/fazer, teoria/prática, numa discussão entre o formar para a vida ou para o mercado de trabalho. Pesquisas sobre Educação Profissional Integrada ao Ensino Médio ressaltam essas dicotomias, apresentam os problemas, os desafios e as possíveis soluções, porém constatam que estes opostos raramente caminham juntos. Dentro deste contexto, este trabalho tem como objetivo, apresentar uma discussão sobre como as práticas discursivas que envolvem a implantação do currículo da Educação Profissional Integrada ao Ensino Médio atravessam discursivamente seus sujeitos e como os discursos que constroem esse território curricular permeiam a formação de seus alunos contribuindo para a (re)produção dos discursos de seus egressos acerca de sua formação profissional. Parte-se do pressuposto de que o sujeito é constituído por discursos, que a escola atua como uma grande maquinaria cultural e social, e que o currículo constitui e institui identidades em seus educandos. Para isso, utilizou-se da pesquisa qualitativa pós-crítica para dar outro olhar a Educação Profissional Integrada ao Ensino Médio, um olhar problematizador, questionador, que retira o foco dos "porquês" e das propostas de soluções, para investigar cuidadosamente, "como" os fatos acontecem. O cenário da pesquisa foi o IFSULDEMINAS - Câmpus Machado e para a constituição do corpus de pesquisa, foram analisadas as leis e decretos que alicerçaram a construção do cenário atual da Educação Profissional, o Projeto Pedagógico do curso Técnico em Informática Integrado ao Ensino Médio e entrevistas semiestruturadas com egressos deste curso. Para as análises e considerações foi utilizado o campo da Análise de Discurso, tendo como ferramenta conceitual a governamentalidade. Seu corpo teórico foi baseado nas relações de poder, governamento e sujeito por Michel Foucault, nas questões sobre currículo e identidade por Alfredo Veiga-Neto, Alice Lopes, Tomaz Tadeu da Silva, a respeito de modernidade líquida por Zigmunt Bauman, entre outros autores. As análises, reflexões e considerações realizadas pelo olhar da governamentalidade em Foucault faz perceber que os sujeitos são sempre controlados, conduzidos e governados de uma maneira ou de outra, através de técnicas, tecnologias, dispositivos de normalização, naturalização e governamento da população que regulam, controlam, constituem e moldam nossas formas de viver, pensar e agir. Percebe-se que escola e a sociedade possuem uma relação de imanência, na qual a escola funciona como um dos dispositivos de governamento dos sujeitos, que pode tanto discipliná-lo aos interesses da sociedade vigente, criando sujeitos governáveis e úteis, como também um locus privilegiado de resistência, de práticas de contraconduta, de reflexão, e que pode atuar na microfísica do exercício do poder e, assim, permitir uma "hipercrítica" das práticas discursivas envolvidas neste território curricular, que possibilite (re)pensar o sujeito e a sociedade.

Palavras-chave: Educação Profissional, Instituto Federal, Currículo Integrado, Governamento.

PERBONI, Edilene Mizael de Carvalho. Os sujeitos das políticas de avaliação sistêmica da alfabetização em minas gerais: uma analítica à luz da governamentalidade. 2015. 188p. Tese (Doutorado em Educação)Programa de Pós-Graduação Stricto Sensu em Educação, Universidade São Francisco, Itatiba, SP. Orientadora: Profa. Dra. Ana Paula de Freitas.

Tudo começa com um sujeito pesquisador, que ao assistir o vídeo - Vida Maria, num encontro da SEE/MG, faz alguns questionamentos sobre o Programa de avaliação da alfabetização em Minas Gerais - PROALFA. Esses questionamentos despertam para o problema de pesquisa: Quais sujeitos e perspectivas curriculares emergem da análise das políticas de avaliação sistêmica da qualidade da alfabetização em Minas Gerais? Para a análise das políticas de avaliação, nos dois primeiros capítulos, são tomados alguns elementos da Análise de Discurso Crítica - ADC, com foco na concepção tridimensional do Discurso: Prática social, Prática discursiva e Texto. O 
capítulo I, à luz da ferramenta analítica da Governamentalidade, aponta para como as políticas de avaliação estão imbricadas em redes de poder produzidas no cenário econômico e político do sistema educacional internacional, nacional e estadual. O capítulo II traz a análise de dois documentos: a Resolução SEE/MG n $1086 / 2008$ e alguns excertos da Matriz de Referência de Teste do SIMAVE/PROALFA. No capítulo III, há um distanciamento da ADC, uma vez que são discutidos os sujeitos avaliados na avaliação sistêmica mineira, na perspectiva de constituição do sujeito em Larrosa, - tecnologias de si e - cuidado de si em Foucault. Nas discussões teóricas do capítulo III, são trazidos dois filmes: - Shrek 1 e - Vida Maria. Quanto aos sujeitos que emergem dessas políticas de avaliação, fazemos dois destaques: primeiro refere-se ao sujeito preconizado nos resultados, que é regulado por regras - anônimas de quem — pode enunciar e o que — pode ser enunciado, de acordo com os padrões de desempenho; o segundo trata-se do sujeito que tem como possibilidade, frente ao próprio processo avaliativo e seus resultados, o - cuidar de si, como - prática de liberdade.

Palavras-chaves: Avaliação Sistêmica (SIMAVE/PROALFA), Sujeito e Governamentalidade.

SANTOS, Jaqueline Aparecida Foratto Lixandrão. A produção de significações sobre combinatória e probabilidade numa sala de aula do $6^{\circ}$ ano do ensino fundamental a partir de uma prática problematizadora. 2015. 191p. Tese (Doutorado em Educação) - Programa de Pós-Graduação Stricto Sensu em Educação, Universidade São Francisco, Itatiba, SP. Orientadora: Profa. Dra. Adair Mendes Nacarato.

Este estudo, que possui cunho qualitativo, procura compreender o que se revela em um trabalho pedagógico com alunos do 60 ano do Ensino Fundamental, feito a partir da perspectiva da problematização, que busca desenvolver o pensamento probabilístico e o raciocínio combinatório por meio de uma articulação entre eles. Baseia-se na perspectiva histórico-cultural, que considera a sala de aula - um ambiente de aprendizagem de alunos e, neste caso, professora-pesquisadora - como contexto de pesquisa, tal como propõe Freitas (2009, 2010). As contribuições da perspectiva histórico-cultural na formação de conceitos científicos, na produção de significações são pautadas em Fontana (2005, 1993), Friedrich (2012), Núñez (2009), Oliveira (2004), Smolka (2010) e Vygotsky (1991, 2001), autores que orientaram o desenvolvimento desta pesquisa. Têm-se como objetivos: reconhecer as ideias que surgem na comunicação oral e escrita em um contexto de problematização em sala de aula, compreender quais tarefas são propícias para o raciocínio combinatório e procurar sinais da contribuição de um estudo da combinatória vinculado ao desenvolvimento do pensamento probabilístico. A pesquisa foi realizada com alunos do $6^{\circ}$ ano do Ensino Fundamental de uma escola da rede estadual de ensino do interior do estado de São Paulo, que realizaram uma sequência de 18 tarefas com foco na linguagem relacionada à combinatória e à probabilidade, bem como no raciocínio combinatório e no probabilístico. Ao final dessas tarefas, os alunos realizaram individualmente outras 5 sobre probabilidade para investigar os indícios do trabalho realizado, de acordo com Hiebert et al (1997). As tarefas propostas foram desenvolvidas a partir dos estudos de Antonio Lopes (2000), Batanero, Godino e Navarro-Pelayo (1994); Celi Lopes (2003); Godino, Batanero e Cañizares (1996); Macedo; Petty; Passos (1997); São Paulo (1998); e Skovsmose (2008). A dinâmica de desenvolvimento das aulas segue as orientações de Christiansen e Walther (1986), que propõem três fases apresentação, atividade independente e reflexão conclusiva. A análise centra-se em dois eixos. No primeiro deles, episódios, estudam-se as ideias de combinatória que emergem em um processo de comunicação oral e escrita, em um contexto de problematização. No segundo eixo, são analisadas as contribuições do estudo da combinatória ao pensamento probabilístico. A partir da análise, é possível observar que os alunos possuem conceitos sobre combinatória e probabilidade e - ao se verem diante de uma proposta de ensino problematizadora, relacionada à linguagem e a uma cultura de aula de Matemática apropriada - podem se envolver em um processo de elaboração conceitual, (re)significando conceitos, atingindo outros mais complexos. Ademais, a articulação da combinatória e da probabilidade com elementos mediadores - linguagem, tarefas e ambiente de aprendizagem - leva à imbricação do raciocínio combinatório e do pensamento probabilístico por meio de significações, permitindo a aprendizagem com compreensão.

Palavras-chave: Raciocínio combinatório. Pensamento probabilístico. Educação Estatística. Ensino e aprendizagem. 
FRARE, Rosangela Eliana Bertoldo. Geometria articulada ao uso do software Sweet Home 3D: mobilização e construção de conceitos no $\mathbf{2}^{\circ}$ ano do ensino médio. 2015. 192 p. Dissertação (Mestrado em Educação). Programa de Pós-Graduação Stricto Sensu em Educação. Universidade São Francisco, Itatiba, SP. Orientadora: Prof. a Dra. Daniela Dias dos Anjos.

O presente trabalho tem como objeto de investigação o processo de ensino e aprendizagem de matemática, desencadeado por uma sequência de tarefas envolvendo a geometria articulada ao uso do software Sweet Home $3 D$, com alunos do $2^{\circ}$ ano do Ensino Médio de uma escola pública estadual situada numa cidade do interior do Estado de São Paulo. Esta pesquisa se baseia na abordagem qualitativa e se constituiu uma pesquisa na própria prática. Para o desenvolvimento da investigação utilizamos o Sweet Home 3D (software de construção de plantas baixas e visualização em 3D) e a resolução de problemas e buscamos analisar o movimento da sala de aula, dos alunos e da professora-pesquisadora, durante o desenvolvimento das tarefas envolvendo a geometria articulada ao uso de software e identificar os conceitos geométricos ali mobilizados e construídos. Os procedimentos metodológicos incluem as transcrições das audiogravações, os arquivos com as construções usando o software, o diário de campo da professora-pesquisadora e os apontamentos dos alunos no caderno. A análise obedeceu a três categorias: a primeira refere-se ao movimento da sala de aula, a segunda aos conhecimentos geométricos mobilizados e construídos durante a realização da pesquisa e a terceira, às reflexões da professora-pesquisadora. Como resultados destacamos a importância da mediação, da problematização e dos registros no movimento de sala de aula para a elaboração e (re)significação conceitual e a variedade de conceitos e procedimentos de resolução envolvendo medidas de comprimento, geometria e grandezas geométricas suscitadas pela resolução de problemas e a utilização do software. Além disso, a pesquisa revelou que a matemática deve fazer sentido para os alunos, que a tecnologia pode mobilizar uma classe para aprender matemática e que, apesar das condições mais adversas, é possível fazer a diferença na sala de aula. Possibilitou a mobilização e a construção não apenas de saberes matemáticos escolares, mas também de saberes não escolarizados. Evidenciou o papel da pesquisa para a reflexão da professora sobre sua própria prática, contribuindo, assim, para seu aprendizado e seu desenvolvimento profissional.

Palavras-chave: Ensino Médio. Resolução de problemas. Geometria. Medidas. Software Sweet Home 3D. 